American Journal of Environmental Sciences 5 (3): 218-222, 2009

ISSN 1553-345X

(C) 2009 Science Publications

\title{
Potential Contribution of Traffic to Air Pollution in the State of Kuwait
}

\author{
N. Al-Mutairi and P. Koushki \\ Department of Civil Engineering, Kuwait University, P.O. Box 5969, Safat 13060, Kuwait
}

\begin{abstract}
Problem statement: The reduction in ambient air pollution is a universal goal-particularly in urban areas, the lack of resources often necessitates identification and prioritization of sources of air pollutants. Efficient planning and effective management of environmental pollutants is thus important for optimum utilization of limited resources. Approach: This study examined seven years of data from three air pollution monitoring stations in the State of Kuwait. The stations-each located at a different district-were selected such that the influence of traffic source and oil refineries/power stations on ambient air pollution contaminants could be detected. A sampling plan was developed and $\mathrm{CH}_{4}, \mathrm{CO}$, $\mathrm{O}_{3}, \mathrm{SO}_{2}, \mathrm{NO}, \mathrm{NO}_{\mathrm{X}}$ and TS concentrations were measured both during peak-traffic hours as well as offpeak hours. Results: Analyses of the data showed that concentrations of the air pollutants had slightly increased over the seven-year study period and only those of the $\mathrm{NO}_{\mathrm{X}}$ and $\mathrm{SO}_{2}$, exceed the permitted standard levels. Traffic was the main source of air pollution in the district located adjacent to the city centre, while oil refineries contributed most to ambient air pollution in the rural district. Conclusion: The concentration levels of $\mathrm{NO}, \mathrm{NO}_{\mathrm{X}}$ and Total Sulfate (TS) were significantly less at the district located away from urban traffic and oil refineries compared to those of with heavy daily traffic congestions and those of the district in proximity to oil refineries.
\end{abstract}

Key words: Air pollution trend, source assessment, urban traffic, oil refinery, Kuwait

\section{INTRODUCTION}

Urbanization processes have increased pollution levels in urban areas, worldwide. Increased population, increased human activity and increased auto ownership, are responsible for most of air pollution emissions in urban environment, e.g., $80 \%$ of $\mathrm{CO}_{2}$ in cities ${ }^{[1]}$. Air pollutants, when released into the atmosphere, pose a direct and serious hazard to living organisms in general and to humans, in particular ${ }^{[2]}$. In addition to the mobile sources of air toxics (traffic), the human-made stationary sources (e.g., building materials, cooking, cleaning) also contribute to the problem of urban air pollution.

The World Health Organization (WHO) refers to six air contaminants that are harmful to human health: carbon monoxide, lead, nitrogen dioxide, sulphur dioxide, ground-level ozone and suspended particulate matter-usually in dust and smoke ${ }^{[3]}$.

In a survey of more than 100 cities in industrial and non-industrial countries, the World Bank has found that the air in many urban areas remains unhealthy ${ }^{[4]}$. The study survey indicated that nearly $29 \%$ of the surveyed cities experienced sulphur dioxide concentrations (often from power plants) in excess of the maximum levels allowable under WHO guidelines and $71 \%$ had nitrogen dioxide concentrations (often from urban traffic) that exceeded WHO maximums.

Oil refineries also heavily pollute the air by emitting more than 100 chemicals into atmosphere. These include metals, particles, sulphur dioxide, nitrogen oxide, carbon dioxide, carbon monoxide, methane, dioxins, hydrogen fluoride, chlorine, benzene and other hazardous gases ${ }^{[5]}$. In addition, oil refineries are also the source for fugitive emissions-the air pollution which escapes through leaks in the equipment. The amount of pollution from fugitive emissions often is higher than that emitted through stacks.

The health impacts of air pollution are more serious than was assumed through most of the twentieth century. Studies have found that the smallest particles of smoke and dust-less than 2.5 microns in size-pose the greatest risk to health ${ }^{[6]}$. Studies in the Czeck Republic and Mexico City have found that the risk to infant death is doubled when urban pollution levels are the highest ${ }^{[7]}$. A 2000 World Bank study has also estimated that an average of 1.8 million people would die (90 thousand of which in the Middle East) prematurely each year in non-industrial countries between 2001 and 2020 because of air pollution ${ }^{[8]}$.

Corresponding Author: N. Al-Mutairi, Department of Civil Engineering, Kuwait University, P.O. Box 5969, Safat 13060, Kuwait Tel: (965)99427676 
The environmental impacts of air pollution are equally grave. The destruction of the ozone layer by Chlorofluorocarbons (CFCs) causes more Ultraviolet (UV) radiation to reach the Earth's surface. High doses of UV can cause cancer, cataracts and reduce immunity to disease $\mathrm{e}^{[9]}$. Acid rain and air pollution are also devastating forests, crops, lakes and building ${ }^{[10]}$.

The environment of Kuwait was severely damaged during the Iraqi invasion of the State in 1990-1991. During this time period, Iraq embarked on a systematic destruction of the State's oil industry and eventually setting fire to 789 oil wells, resulting in catastrophic impacts on the environment and the economy ${ }^{[11]}$. Studies have indicated that the ecological landscape of Kuwait and the Arabian Gulf was irrevocably damaged due to the burning oil wells ${ }^{[12]}$.

The health impact of the oil well fires was also immense. In a study, a telephone survey of 10,051 ill Gulf War veterans found those reporting breathing or enveloped in oil fire smoke, suffered from a number of symptoms including fatigue, skin rash, muscle and join pain, headache, loss of memory, shortness of breath and gastrointestinal problems ${ }^{[13]}$.

The review of literature indicates that in spite of the likely adverse health and environmental impacts of air pollution in Kuwait, no analysis of air pollution trend or source identification has been made in recent years. It is the narrowing of this research gap that this study is addressed to.

The objectives of the study were to:

- Examine trends in air pollution in Kuwait

- Determine the likely contribution of urban traffic and oil refineries as sources of air pollution contaminants

\section{MATERIALS AND METHODS}

The study area and the data: The oil-rich State of Kuwait is located at the north western corner of the Arabian Gulf, bordering with Iraq and Saudi Arabia. The total area of the State is 17,818 sq. $\mathrm{km}$ (approximately $7000 \mathrm{sq}$. mi.). The weather is typical of the desert geographical region. The total annual rainfall has been steadily increasing in recent years- $80.8(\mathrm{~mm})$, in 2000, to 216.8 (mm), in 2004 (MOP, 2004). Most of the annual rainfall is between November and February. The mean monthly temperature over the last 42 year period (1957-2004), was $26^{\circ} \mathrm{C}$ and in nearly five months in a year, the afternoon temperature can rise to $45^{\circ} \mathrm{C}$. This overwhelming heat has been the main cause of an annual per capita energy consumption increase rate of $7.7 \%$. In industrial nations, this rate is between $2-3 \%{ }^{[14]}$.
The State has a population of over 2.65 million of which more than 1.7 million are non-Kuwaitis. The State's labor force includes nearly 1.6 million employed individuals, 770,000 of which are semi-skilled laborers ${ }^{[15]}$. Auto is, by far, the principle mode of travel in metropolitan Kuwait. An average employed individual in Kuwait makes 6.1 trips per day, each with a mean trip length of $13.6 \mathrm{~km}$. More than 68 minutes of time-delay is experienced in traffic congestion by an average employed individual, each day ${ }^{[16]}$. In the year 2005, the employed individuals' travel generated 31,275 tons of Volatile Organic Compound (VOC); 247,764 tons of carbon monoxide (CO); 19,594 tons of nitrogen oxides $\left(\mathrm{NO}_{\mathrm{X}}\right) ; 1,703$ tons of sulphur dioxide $\left(\mathrm{SO}_{2}\right)$ and more than 6 million tons of carbon dioxide. While, traffic is the main source of air pollution in Kuwait urban area, power stations and oil refineries contribute the most to air pollution emissions in rural areas of the State.

Seven years (1998-2004), of data from three Air Monitoring Stations of Kuwait Environmental Public Authority (KEPA) were obtained for the analysis. These included the mean monthly concentrations of $\mathrm{CH}_{4}, \mathrm{CO}, \mathrm{O}_{3}, \mathrm{SO}_{2}, \mathrm{NO}, \mathrm{NO}_{\mathrm{X}}$ and Total Sulfate (TS). The three stations were chosen such that one would represent a central urban district with high traffic density (Mansoria); the other a district in the proximity of oil refineries (Reqa) and the third, a rural district in between these districts (Rabia). The distance between the three air pollution monitoring stations, are approximately $25 \mathrm{~km}$, each. In addition, data were also collected on meteorological characteristics:

Temperature, humidity, wind speed and wind directions for the seven-year study period. The data were then compiled in the memory of computers of the College of Engineering and Statistical Analysis Software (SAS) were employed to process and analyze the data.

\section{RESULTS AND DISCUSSION}

The concentrations of $\mathrm{CO}$ air pollution in Mansoria (a district adjacent to the city center), has shown a fluctuating trend since 1998, reaching a low level in 2000-2001 and then rising slightly in 2003-2004. Although, a moderate increase in $\mathrm{CO}$ concentrations is observable over the winter months (Fig. 1), the mean monthly levels are well below the $8 \mathrm{~h}$ average of 9 (ppm). A study of air pollution concentrations inside parking structures also found that even in enclosed parkings, the level of $\mathrm{CO}$ rarely violated the maximum permitted standards ${ }^{[17]}$. 


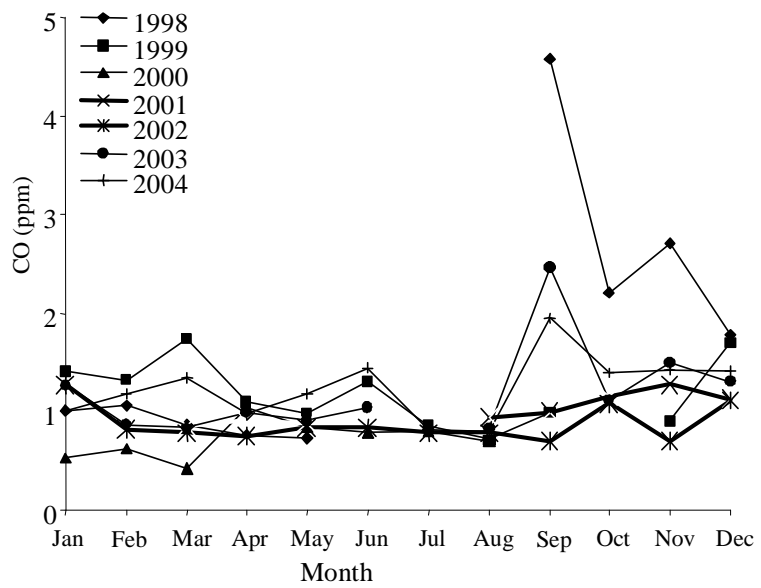

Fig. 1: Monthly air pollutant (CO) in Mansoria over seven year period

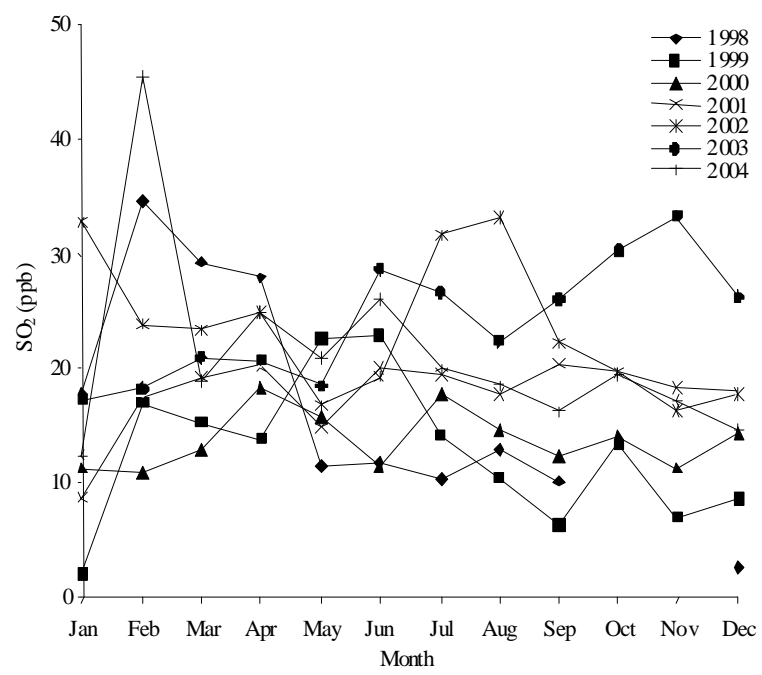

Fig. 2: Monthly air pollutant $\left(\mathrm{SO}_{2}\right)$ in Reqa over seven year period

The distribution of the monthly mean $\mathrm{SO}_{2}$ levels in Reqa-a district close to oil refineries), over the sevenyear study period, while showing a wider range of fluctuation from year to year when compared to $\mathrm{CO}$, have generally increased in recent years (Fig. 2). A slight increase in $\mathrm{SO}_{2}$ level over the winter months is also noticeable.

Nitrogen Oxide concentration levels in Rabia, clearly peak in winter months and have increased rather considerably over the study period. As shown in Fig. 3, the summer months of June, July and August, have experienced the lowest levels of NO in the last 7 years. One major factor contributing to the lower levels of air pollution emissions over the summer season is the fact that the majority of the population in Kuwait-especially

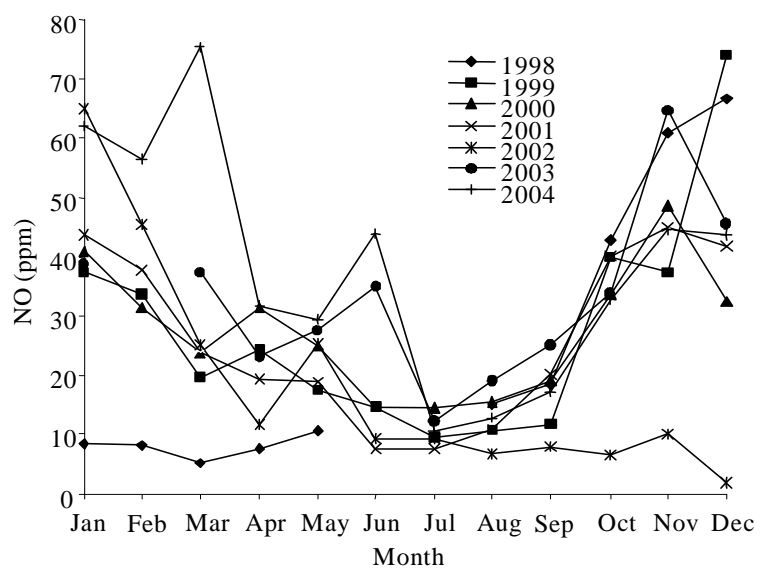

Fig. 3: Monthly air pollutant (NO) in Rabia over seven year period

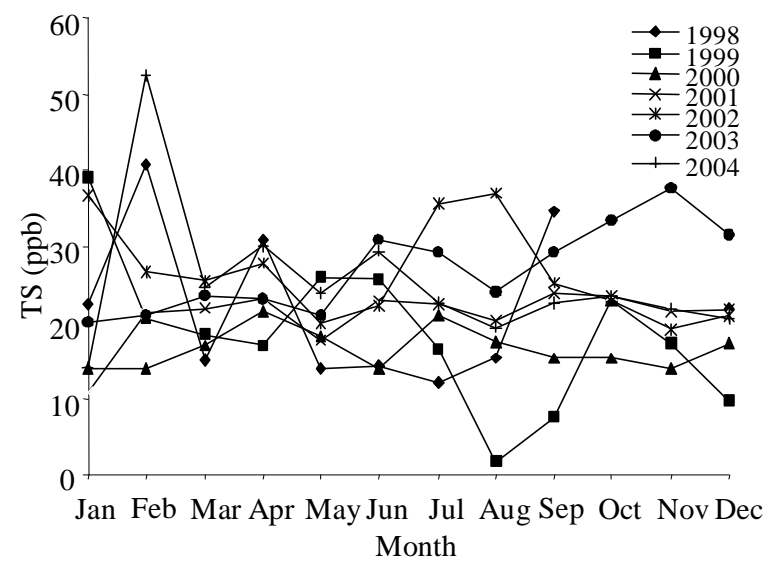

Fig. 4: Monthly air pollutant TS in Reqa over seven year period

the non-Kuwaiti professionals-leave the State for summer vacation. This will considerably reduce the traffic contribution to air pollution emissions over the summer months.

Nearly, 2/3 of the population in the State of Kuwait are expatriates ${ }^{[15]}$. A similar trend was also found to exist in the monthly mean concentrations of $\mathrm{NO}_{\mathrm{X}}$ over the 7-year study period.

Total Sulfur (TS) concentrations in Reqa (in proximity to oil refineries) have generally increased with time, reaching a maximum level in 2003-2004. Figure 4, shows fluctuations of TS at Reqa district for the 1998-2004 study period. The increase in the concentration level of TS over the winter months, especially in recent years is also noticeable from the data in Fig. 4. 
Am. J. Environ. Sci., 5 (3): 218-222, 2009

Table 1: Significant difference in the district mean monthly concentrations of $\mathrm{NO}, \mathrm{NO}_{\mathrm{x}}$, and TS

\begin{tabular}{|c|c|c|c|c|c|c|}
\hline \multirow[b]{2}{*}{ Emission/districts compared } & \multicolumn{2}{|c|}{ Mean concentrations } & \multicolumn{2}{|c|}{ Standard deviation } & \multirow{2}{*}{$\begin{array}{l}\text { Computed } \\
\hat{Z}\end{array}$} & \multirow{2}{*}{$\begin{array}{l}\text { Hypo. Test: }^{\mathrm{a}} \\
\mathrm{H}_{0}: \overline{\mathrm{X}}_{1}=\overline{\mathrm{X}}_{2} \\
\mathrm{H}_{1}: \overline{\mathrm{X}} \neq \overline{\mathrm{X}}_{2}\end{array}$} \\
\hline & $\overline{\mathrm{X}}_{1}$ & $\overline{X_{2}}$ & $\mathrm{~S}_{1}$ & $\mathrm{~S}_{2}$ & & \\
\hline \multicolumn{7}{|l|}{ NO } \\
\hline Mansoria vs Rabia & 128.0 & 44.0 & 96.20 & 17.9 & 2.26 & $\mathrm{H}_{0}$ : rejected \\
\hline Reqa vs Rabia & 94.1 & 44.0 & 32.70 & 17.9 & 3.52 & $\mathrm{H}_{0}$ : rejected \\
\hline Mansoria vs Reqa & 128.0 & 94.1 & 96.20 & 32.7 & 0.89 & $\mathrm{H}_{1}$ : rejected \\
\hline \multicolumn{7}{|l|}{$\mathrm{NO}_{\mathrm{x}}$} \\
\hline Mansoria vs Rabia & 185.6 & 65.0 & 128.80 & 29.0 & 2.40 & $\mathrm{H}_{0}$ : rejected \\
\hline Reqa vs Rabia & 139.5 & 65.0 & 30.70 & 29.0 & 4.62 & $\mathrm{H}_{0}$ : rejected \\
\hline Mansoria vs Reqa & 185.6 & 139.5 & 128.80 & 30.7 & 0.80 & $\mathrm{H}_{1}$ : rejected \\
\hline \multicolumn{7}{|l|}{ TS } \\
\hline Mansoria vs Rabia & 31.9 & 14.1 & 10.90 & 20.8 & 2.01 & $\mathrm{H}_{0}$ : rejected \\
\hline Reqa vs Rabia & 28.0 & 14.1 & 13.60 & 20.8 & 1.61 & $\mathrm{H}_{0}:$ rejected $^{\mathrm{b}}$ \\
\hline Mansoria vs Reqa & 31.9 & 28.0 & 10.90 & 13.6 & 0.59 & $\mathrm{H}_{1}:$ rejected \\
\hline
\end{tabular}

${ }^{a}$ : Significance level: $95 \%{ }^{b}$ : Significance level: $90 \%$

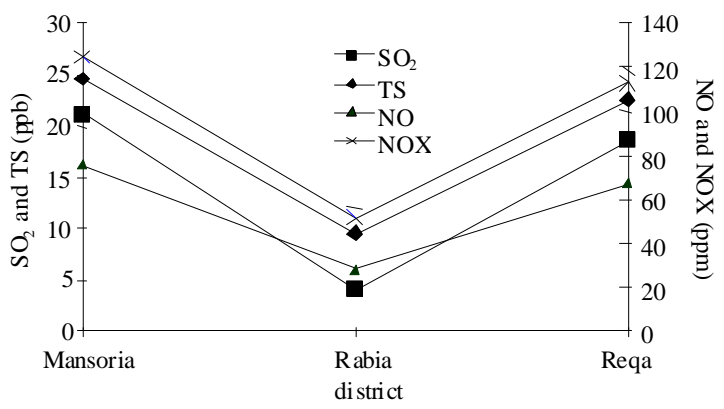

Fig. 5: Mean monthly atmospheric pollution levels by district: 1998-2004

The significance of the contribution of urban traffic and oil refineries to concentrations of air pollutants in Kuwait is highlighted in Fig. 5. The Mansoria district with its central location in Kuwait urban area is characterized by high traffic volumes and daily congestions. The Reqa district on the other hand is located far away from Kuwait urban area and is characterized by low-density population and low traffic volumes, but in close proximity of oil refineries. The Rabia district is located in-between Mansoria and Reqa and is characterized by sparse single-unit housing, small population and very low traffic volumes throughout the day.

As the data in Fig. 5 signifies, the ambient concentrations of $\mathrm{SO}_{2}, \quad \mathrm{TS}$, $\mathrm{NO}$ and $\mathrm{NO}_{\mathrm{X}}$ are considerably higher in Mansoria (traffic contribution) and in Reqa (refinery contribution), when compared to those monitored at the Rabia district. The increases in pollution concentration levels in Mansoria, compared to those in Rabia are: $\mathrm{SO}_{2}$ (557\%); $\mathrm{NO}$ (129\%); TS $(150 \%)$ and $\mathrm{NO}_{\mathrm{X}}(125 \%)$. Similar differences in air pollution emissions exist between Reqa and Rabia. The traffic and refinery contribution level to sources of air pollutions in the State of Kuwait are therefore clear from the data in Fig. 5.

The analysis of the concentrations of the air pollution emissions from the three monitoring stations have shown that only the mean monthly level of total sulphate (for which no standard level is found in the literature) and oxides of nitrogen were above the standard limits. As indicated previously, the three monitoring stations were selected such that the level of contribution of urban traffic and oil refineries to air pollution emissions could be detected. A test of significant difference between the mean concentrations of $\mathrm{NO}, \mathrm{NO}_{\mathrm{X}}$ and $\mathrm{TS}$ in the selected districts was performed on the data. As is shown in Table 1, the difference in the mean monthly concentrations of NO between Mansoria (urban center district) and Rabia (the in-between district away from the city and oil refineries) was statistically significant at the $99 \%$ significant level. The same was true of that between Reqa (district with oil refineries) and Rabia. In other words, the mean monthly NO concentration levels at the city-center district and the district close to the oil refineries were significantly higher than those measured at the in-between district. No significant difference in NO levels however was found to exist between those at the city-center and the oil refinery districts. The data in Table 1 also shows similar trends for both the $\mathrm{NO}_{\mathrm{X}}$ and the TS concentration levels at the three study districts.

\section{CONCLUSION}

The analysis of the impact of urban auto-traffic and oil refineries on concentration levels of atmospheric air pollution were performed on data from three monitoring stations. The concentration levels of NO, $\mathrm{NO}_{\mathrm{X}}$ and Total Sulfate (TS)-which are generally highwere significantly less at the district located away from both sources of air pollutants (urban traffic and oil 
refineries) compared to those of the urban center district (heavy daily traffic congestions) and those of the district in proximity to oil refineries. In the absence of any long-term policy plans to curb the rapidly growing urban population, auto ownership and increasing oil productions, the quality of the air in the State of Kuwait will continue to worsen. The urban policy makers should focus attention on numerous ways to curb both, the growing reliance on auto travel and the increasing rate of oil production, if the long-term health and the quality of life of the public is to be maintained.

\section{REFERENCES}

1. Koerner, B. and J. Klopatek, 2002. Anthropogenic and natural $\mathrm{CO}_{2}$ emission sources in an arid urban environment. Environ. Pollut., 116: 45-51. DOI: 10.1016/S0269-7491(01)00246-9

2. Pearson, R., H. Wachtel and K. Ebi, 2000. Distance-weighted traffic density in proximity to a home is a risk factor to leukaemia and other childhood cancers. J. Air Waste Manage. Associat., 50: $175-180$.

http://www.ncbi.nlm.nih.gov/pubmed/10680346

3. World Health Organization and European Environment Agency, 1997. Air and Health-Local Authorities, Health and Environment, Copenhagen, pp: 3.

4. World Bank, 2003. World Development Indicators. Illustrated Edn., World Bank Publications, Washington, DC., pp: 391. ISBN: 0821354221.

5. Warneck, P., 1988. Chemistry of the Natural Atmosphere. Academic Press, San Diego, New York, pp: 757. ISBN: 0127356304.

6. Harder, B., 2004. No deep breathing-air pollution impedes lung development. Sci. News, 166: 163. http://cat.inist.fr/?aModele $=$ afficheN\&cpsidt $=1609$ 7035

7. Cifuentes, L., H. Victor, Borja-Aburto, N. Gouveia, G. Thurston and D. Lee Davis, 2001. Hidden health benefits of greenhouse gas mitigation. Science, 293: 1257-1259. DOI: 10.1126/science. 1063357
8. World Bank, 2000. Fuel for Thought: An Environmental Strategy for the Energy Sector. World Bank Publications, Washington DC., USA., pp: 118. ISBN: 0821345990.

9. EEA, 1997. Air and Health-Air Pollution and Global Effects. European Environment Agency, Copenhagen, pp: 9.

10. Postel, S., 1984. Air Pollution, Acid Rain and the Future of Forests. World Watch Institute, Washington DC., pp: 58. ISBN-0-916468-57-7.

11. Krupa, M., 1997. Environmental and economic repercussions of the persian gulf war on Kuwait. ICE Case Studies. http://www.american.edu/ted/ice/kuwait.htm

12. Trade and Environment Database, 1994. The economic and environmental impact of the Gulf war on Kuwait and the Persian Gulf. http://www.american.edu/TED/KUWAIT.HTM

13. Stead, C., 2004. Oil smoke as a cause of illness in Gulf War Veterans. The National Gulf War Resource Center, Inc.

14. Al-Temeemi, A., 1995. Climatic design techniques for reducing cooling energy consumption in Kuwaiti houses. Energy Build., 23: 41-48. DOI: 10.1016/0378-7788(95)00915-K

15. MOP., 2004. Statistics and Census Sector (SCS). Ministry of Planning, Kuwait. http://unstats.un.org/unsd/statcom/statcom_seminar /kuwait.pdf

16. Koushki, P., 2007. Personal cost of auto travel in Kuwait. J. Transport. Engrg., 133: 275-280. DOI: 10.1061/(ASCE)0733-947X(2007)133:4(275)

17. Khajah, K., 2005. Toxic air pollution in urban parking structures in Kuwait. MS Project, Civil Engineering Department, Kuwait University. 